\title{
Sequential Devices Occlusion of Post-Surgical Ascending Aorta Pseudoaneurysms in a Child, Case Report
}

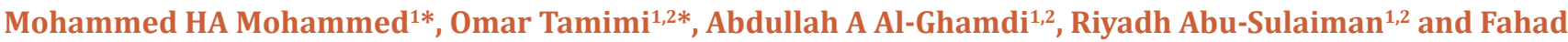 \\ Alhabshan ${ }^{1,2}$ \\ ${ }^{1}$ Cardiac Sciences Department, King Abdulaziz Cardiac Center-National Guard Health Affairs, Kingdom of Saudi Arabia \\ ${ }^{2}$ King Saud Bin Abdulaziz University for Health Sciences, Saudi Arabia
}

Submission: October 03, 2017; Published: November 06, 2017

*Corresponding author: Mohammed HA Mohammed, Pediatric Cardiology Division, Cardiac Sciences Department King Abdulaziz Cardiac Center, MC 1413, P.O. Box 22490, Riyadh 11426, Saudi Arabia, Tel: +966 11801 6771; Fax: +966 11801 1111, ext. 16773 ;

Email: drmohammedhassan100@hotmail.com

Omar Tamimi, King Abdulaziz Cardiac Center, MC 1413, P.0. Box 22490, Riyadh 11426, Saudi Arabia, Tel: +966 $118016771 ;$ Fax: +966 11801

1111, ext. 16773; Email: drtamimi@hotmail.com

\begin{abstract}
Pseudoaneurysm of ascending aorta is an infrequent but well recognized and potentially fatal complication after cardiac surgery. This complication can develop early and late after surgery with variable presentation. We are reporting a case of pseudoaneurysm of ascending aorta following cardiac surgery at the site of cardioplegia needle and aortic cannulation that were successfully managed by percutaneous catheter based-placement of two devices in two occasions with fluoroscopic and two and three dimensional transesophageal echocardiography (TEE) guidance. The first device was an Amplatzer duct occluder type II at the cardioplegia needle site. The other aneurysm was located at the aortic cannulation site and was closed using an Amplatzer atrial septal occluder size $5 \mathrm{~mm}$. An immediate post procedure TEE and a Transthoracic Echocardiography at hospital discharge showed no residual leak and no obstruction to the aortic flow.
\end{abstract}

Keywords: Pseudoaneurysm; Device; Catheterization; Amplatzer

\section{Introduction}

Post-cardiac surgery pseudoaneurysms are rare and potentially lethal complications with an incidence of less than $0.5 \%$ of all procedures $[1,2]$. Other common potential etiologies include endocarditis and trauma [3]. Majority of the patients are asymptomatic while the clinical symptoms are usually related to mass effect on the surrounding structures [4]. The catastrophic complication which can lead to death is a rupture of the pseudoaneurysm. Other significant complications include thrombosis, thromboembolism and fistula formation [5]. The mortality rate may reach up to $61 \%$ if it remains untreated [6]. Surgical repair of this condition is challenging with a reported risk of mortality rate that ranges between $29 \%$ and $46 \%$. Exsanguination resulting from rupture of the pseudoaneurysm during sternal re-opening or surgical maneuvers is the most frequent cause of death $[1,6,7]$. Options for repair other than surgery, include endovascular graft placement, thrombin injection, coil embolization and more recently, percutaneous device closure [8-14]. We report a case of ascending aortic pseudoaneurysm that developed within 2 months after open heart surgery at two different sites and onset time and they were sequentially closed by percutaneous trans-catheter devices.

\section{Case Report}

A 16 year old girl with asymptomatic severe mitral regurgitation underwent surgical mitral valve repair with no immediate complications. During the same admission, however, the patient was observed to have poor wound healing and she developed sternal wound infection and wound gapping which was treated with antibiotics and surgical debridement. Transthoracic echocardiography (TTE) showed evidence of infective endocarditis with a large vegetation on the mitral valve so antibiotic treatment prolonged. While she is stay for infective endocarditis, she developed fever, tachycardia and hypotension. Her hemoglobin level dropped from 11.5 to $8.7 \mathrm{gram} / \mathrm{dl}$. A chest 
x-ray showed a widening of the mediastinum. TTE showed a large pseudoaneurysm measuring $5 \times 7 \mathrm{~cm}$ in diameter around the anterior part of the ascending aorta. There was blood flow to and from the ascending aorta into the pericardial space (Figure $1 \mathrm{~A} \& 1 \mathrm{~B})$. The pseudoaneurysm was thought to be arising from the cardioplegia needle site which was sutured after surgery but developed dehiscence of the sutures later due to infective endocarditis. The patient was given a blood transfusion. The patient's condition was discussed and it was decided for an urgent intervention due to the significant hemoglobin drop and to avoid the risk of pseudoaneurysm rupture and death. Due to the high risk of surgical repair, an attempt of transcatheter closure of the pseudoaneurysm was planned. Two and three-dimensional transesophageal echocardiography (TEE) was performed and showed a large pseudoaneurysm measuring $6 \times 5 \mathrm{~cm}$ anterior and superior to the ascending aorta, a communicating hole of $0.4 \times 0.4 \mathrm{~cm}$ in size with bidirectional flow was noted (Figure 1C $\&$ 1D). The opening of the pseudoaneurysm was successfully closed using a $4 \times 4 \mathrm{~mm}$ Amplatzer Duct Occluder II device (9PDA2-04-04 St. Jude Medical, Inc. St. Paul, MN) which was delivered via a 5Fr sheath. Post-procedure TEE showed that the device was well seated with no residual communication between the pseudoaneurysm and the ascending aorta. Immediate partial clotting of the pseudoaneurysm was noted after the procedure (Figure 1E \& 1F). The patient was kept in the hospital to complete the treatment for infective endocarditis. However, twenty days later TTE showed another new pseudoaneurysm at the aortic cannula site. The prior device was seen at the site of previous pseudoaneurysm with no residual leak. An urgent Computerized Tomographic (CT) angiogram was done and revealed another aortic pseudoaneurysm surrounding the ascending aorta at the aortic cannula site, while the previous device was seen in position (Figure 2A \& 2B).

Transcatheter closure of the pseudoaneurysm was planned. TEE showed that the second pseudoaneurysm is measuring $1.1 \times 1.3 \mathrm{~cm}$ with a communicating hole of $0.3 \times 0.5 \mathrm{~cm}$ in size (Figure 2C \& 2D). The opening of the pseudoaneurysm was at the site of previous aortic cannulation which was thought to have developed because of dehiscence of the sutures as well due to infection, so it was successfully closed using a 5x5mm Amplatzer atrial septal occluder device (St. Jude Medical, Inc. St. Paul, MN) which was delivered via a 7Fr sheath. Postprocedure TEE showed that the device was well seated with no residual communication between the pseudoaneurysm and the ascending aorta (Figure $2 \mathrm{E} \& 2 \mathrm{~F})$.

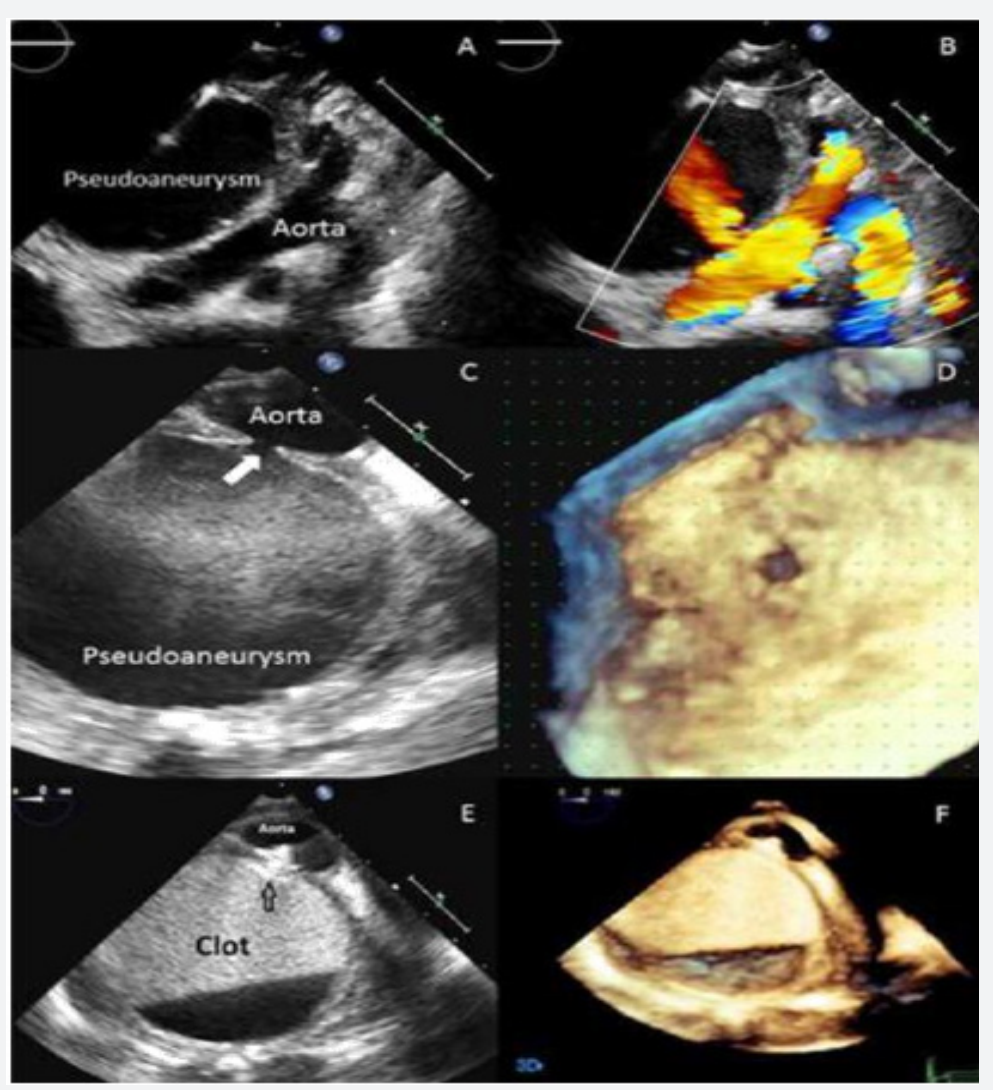

Figure 1A-F: 2D-Transthoracic echocardiography (A and B) suprasternal view showing large pseudo aneurysm measuring $5 \times 7 \mathrm{~cm}$ in diameter around the anterior part of the ascending aorta. There was blood flow to from the ascending aorta into the pericardial space. 2-3D transesophageal echocardiography $(C$ and $D)$ pre device closure showing a large pseudo aneurysm measuring $6 \times 5 \mathrm{~cm}$ anterior and superior to the ascending aorta, a communicating hole of $0.4 \times 0.4 \mathrm{~cm}$ in size $(E$ and $D)$ post device closure showing Immediate partial clotting of the pseudo aneurysm was noted after the procedure well seated device (arrow). 


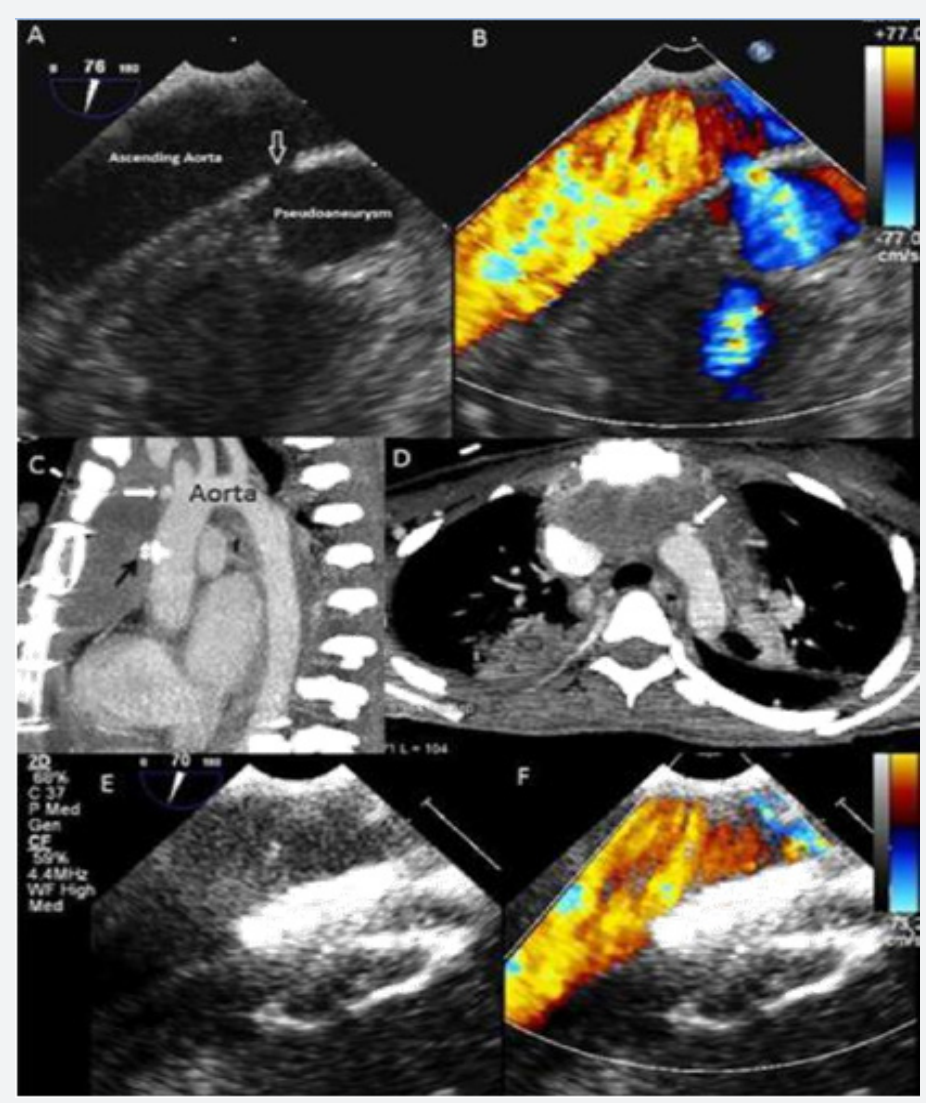

Figure 2A-F: 2D-Transesophageal echocardiography pre (A and B) and post device closure of the second pseudo aneurysm. Computerized Topographic (CT) angiogram (C and D) showing the second pseudo aneurysm surrounding the ascending aorta while the previous device was seen in position.

The patient stayed in the hospital for few more days and was then discharged home in a stable condition after completion of the antibiotics course.

\section{Discussion}

Perioperative factors that contribute to the development of pseudoaneurysms include infection, poor suturing technique, aortopathy and other factors. Our patient was observed to have poor wound healing and she developed also infective endocarditis which could be the cause for this pseudoaneurysm formation $[1,2,11]$. The dehiscence of the aortic cannulation was thought to be part of the poor wound healing hurdle which augmented the pseudoaneurysm complication. Majority of the patients $(80 \%)$ who were reported to have postoperative pseudoaneurysm presented within two weeks after surgery [11]. Our patient had a delayed presentation which could be due to the antibiotic treatment of the wound infection. Series of case reports have shown encouraging results of percutaneous catheter-based intervention for non-surgical treatment of pseudoaneurysm. They were published with off label device use which we have followed in our patient twice [4,5,8-14].

Similar to other reported experiences about the treatment of this fatal complication, we report the successful result of transcatheter device closure of aortic pseudoaneurysm. This represents an alternative safe and effective management with excellent short term outcome.

\section{Acknowledgment}

Special thanks to Professor Talat Yelbuz for his revision of this manuscript.

\section{References}

1. Sullivan K, Steiner R, Smullens S (1998) Pseudo aneurysm of the ascending aorta following cardiac surgery. Chest 93(1): 138-143.

2. Katsumata T, Moorjani N, Vaccari G (2000) Mediastinal false aneurysm after thoracic aortic surgery. Ann Thorac Surg 70(2): 547-552.

3. Razzouk A, Gundry S, Wang N (1993) Pseudoaneurysms of the aorta after cardiac surgery or chest trauma. Am Surg 59(12): 818-823.

4. Noble S, Ibrahim R (2012) Embolization of an amplatzer mVSD occluder device used for percutaneous closure of an ascending aortic pseudoaneurysm: case report and literature review. Catheter Cardiovasc Interv 79(2): 334-338.

5. Bashir F, Quaife R, Carroll J (2005) Percutaneous closure of ascending aortic pseudoaneurysm using Amplatzer septal occluder device: the first clinical case report and literature review. Catheter Cardiovasc Interv 65(4): 547-551.

6. Mulder E, van Bockel J, Maas J (1998) Morbidity and mortality of reconstructive surgery of noninfected false aneurysms detected long after aortic prosthetic reconstruction. Arch Surg 133(1): 45-49. 
7. Dougenis D, Daily B, Kouchoukos N (1997) Reoperation on the aortic root and ascending aorta. The Annals of Thoracic Surgery 64(4): 986992

8. Lin P, Kougias P, Huynh T (2007) Endovascular repair of ascending aortic pseudoaneurysm: Technical considerations of a common carotid artery approach using the Zenith aortic cuff endograft. J Endovasc Ther 14(6): 794-798.

9. Kumar P, Alli O, Bjarnason H (2012) Percutaneous therapeutic approaches to closure of cardiac pseudoaneurysms. Catheter Cardiovasc Interv 80(4): 687-699.

10. Hussain J, Strumpf R, Wheatley G (2009) Percutaneous closure of aortic pseudoaneurysm by Amplatzer occluder device case series of six patients. Catheter Cardiovasc Interv 73(4): 521-529.

11. Atik F, Navia J, Svensson L (2006) Surgical treatment of pseudoaneurysm of the thoracic aorta. J Thorac Cardiovasc Surg 132(2): 379-385.

12. Kanani RS, Garasic JM, Palacious IF (2007) Percutaneous closure of ascending aortic aneurysms. Catheterization Cardiovascular Interventions 70(4): 621

13. Agarwal M, Ray M, Pallavi M (2011) Device occlusion of pseudoaneurysm of ascending aorta. Ann Pediatr Cardiol 4(2): 195-199.

14. Hussain J, Strumpf R, Ghandforoush A (2010) Transcatheter closure of recurrent aortic pseudoaneurysm previously treated by Amplatzer occluder device. J Vasc Surg 52(1): 196-198.

\section{Your next submission with Juniper Publishers} will reach you the below assets

- Quality Editorial service

- Swift Peer Review

- Reprints availability

- E-prints Service

- Manuscript Podcast for convenient understanding

- Global attainment for your research

- Manuscript accessibility in different formats

( Pdf, E-pub, Full Text, Audio)

- Unceasing customer service

Track the below URL for one-step submission https://juniperpublishers.com/online-submission.php 